\title{
Assessment of Groundwater Quality Based on Matter Element Extension Model
}

\author{
Jin Jing, ${ }^{1}$ Qian Hui, ${ }^{1,2}$ Chen Yu-Fei, ${ }^{1}$ and Xi Wen-Juan' \\ ${ }^{1}$ College of Environmental Science and Engineering, Chang'an University, No.126 Yanta Road, Xian, Shaanxi 710054, China \\ ${ }^{2}$ Key Laboratory of Subsurface Hydrology and Ecology in Arid Areas, Ministry of Education, No.126 Yanta Road, Xian, \\ Shaanxi 710054, China \\ Correspondence should be addressed to Jin Jing; niepanyaoji@163.com
}

Received 13 March 2012; Revised 8 June 2012; Accepted 11 June 2012

Academic Editor: Jorge F. Fernandez-Sanchez

Copyright (C) 2013 Jin Jing et al. This is an open access article distributed under the Creative Commons Attribution License, which permits unrestricted use, distribution, and reproduction in any medium, provided the original work is properly cited.

\begin{abstract}
The basic theory and calculating processes of matter element extension method are discussed in detail. Mass balance simulation is used to study the changes of groundwater chemistry. Results show that calcite and dolomite are oversaturated, while gypsum, fluorite, and halite are unsaturated in the simulation path; so calcite precipitates, while gypsum, fluorite, halite, and dolomite dissolve. The changing tendency of $\mathrm{Ca}^{2+} / \mathrm{Na}^{+}$is apparent. Because of the dissolution and precipitation of minerals, the content of each ion changes. Parameters of groundwater are basically within the permissible limits and meet the requirement of drinking water standards. By comparing the evaluation results obtained from matter element extension method, osculating value method based on entropy weight, and principal component analysis method, it is proved that matter element extension is an effective and reasonable method for groundwater quality assessment. The converting tendency of groundwater quality is judged based on the extension indexes; this characteristic is unique of matter element extension method.
\end{abstract}

\section{Introduction}

Groundwater is the most important water resource for human. Groundwater quality problems have intensified through the ages in response to the increased growth on concentration of populations and industrial centres and unreasonable exploitation and utilization of groundwater. Thus finding an objective and reasonable method to evaluate water quality is a hot issue at the present time.

Today there are a lot of methods to evaluate goundwater quality, such as water quality index method [1], grey correlation method [2], principal component analysis method [3], and fuzzy theory method [4] and fuzzy synthetic evaluation method [5]; every method has its weakness, such that water quality index evaluation method is subjective, and grey clustering method and fuzzy theory method neglect some important information in the process of calculation and need special program to finish the complicated calculation. Matter element extension method can solve the realistic contradiction qualitatively and quantitatively [6]. It has been applied to many fields, such as environmental quality assessment
[7], land suitability evaluation [8], and risk assessment of urban network planning [9], but the application on evaluating groundwater quality is less. In this paper, we combine the method and information entropy to evaluate groundwater quality of water source of Shizuishan city NW China; the grade of groundwater quality is obtained by calculating the comprehensive correlation degrees and extension indexes [6]. The comprehensive analysis is done based on parameters analysis and mass balance simulation.

\section{Method}

Matter element extension, incorporating the matter element theory with extension theory [3], was proposed by Mr. Cai in the 1980s. Its basic theory is outlined below.

2.1. Definition of Matter Element. A given thing is named $M$, whose characteristic $c$ is valued $v$, the orderly ternary group $R=(M, C, V)$ is named as the matter element. $M$ has $n$ characteristics $c_{1}, c_{2}, \ldots, c_{n}$ and the corresponding values are 
$v_{1}, v_{2}, \ldots, v_{n}$; thus the matter element can be expressed as [711]:

$$
R(x)=\left[\begin{array}{lll}
M & c_{1} & v_{1} \\
& c_{2} & v_{2} \\
& M & M \\
& c_{n} & v_{n}
\end{array}\right]
$$

according to the definition of matter element, the classical domain $R_{0}$ and section domain $R_{c}$ can be determined.

2.2. Construction of the Correlation Function. The correlation degree of each characteristic to each class can be calculated by using the following functions [7-11]:

$$
K_{j}\left(x_{i}\right)= \begin{cases}-\frac{\rho\left(x_{j}, x_{i j}\right)}{\left|x_{i j}\right|} & x_{j} \in x_{i j} \\ \frac{\rho\left(x_{j}, x_{i j}\right)}{\rho\left(x_{j}, x_{p j}\right)-\rho\left(x_{j}, x_{i j}\right)} & x_{j} \notin x_{i j},\end{cases}
$$

where $\left|x_{i j}\right|=\left|a_{i j}-b_{i j}\right|$,

$$
\begin{array}{r}
\rho\left(x_{j}, x_{i j}\right)=\left|x_{j}-\frac{1}{2}\left(a_{i j}-b_{i j}\right)\right|-\frac{1}{2}\left(b_{i j}-a_{i j}\right) \\
i=1,2, \ldots, m, j=1,2, \ldots, n \\
\rho\left(x_{j}, x_{p j}\right)=\left|x_{j}-\frac{1}{2}\left(a_{p j}-b_{p j}\right)\right|-\frac{1}{2}\left(b_{p j}-a_{p j}\right) \\
j=1,2, \ldots, n .
\end{array}
$$

2.3. Weight Determination. There are many widely used methods, such as principal component analysis [3], and AHP [12]. These methods are subjective and random to some extent. Information entropy [13] is used to determine the weights of evaluated indexes in this study; it minimizes the subjective influence, and the result is more objective and reasonable.

2.4. Comprehensive Correlation Degree $K_{i}(P)$ and Extension Index $j{ }^{*}$ Calculation. The comprehensive correlation degrees of evaluated samples can be obtained

$$
K_{i}(p)=\sum_{j=1}^{n} W_{j} \cdot K_{j}\left(x_{i}\right) \quad i=1,2, \ldots, m ; j=1,2, \ldots, n .
$$

Suppose

$$
\overline{K_{i}(p)}=\frac{K_{i}(p)-\min K_{i}(p)}{\max K_{i}(p)-\min K_{i}(p)} \quad i=1,2, \ldots, m .
$$

The formula for calculating the extension index $j^{*}$ is

$$
j^{*}=\frac{\sum_{i=1}^{m} i \cdot \overline{K_{i}(p)}}{\sum_{i=1}^{m} \overline{K_{i}(p)}} \quad i=1,2, \ldots, m .
$$

The grade of evaluated object and the attributive degree of the evaluated matter element tend to convert into adjacent levels can be judged from $j^{*}[14,15]$.

\section{Case Study and Materials}

3.1. Study Area. The water source of Shizuishan City is located between latitude $38^{\circ} 57^{\prime} 18^{\prime \prime}-39^{\circ} 04^{\prime} 04^{\prime \prime} \mathrm{N}$ and longitude $106^{\circ} 25^{\prime} 09^{\prime \prime}-106^{\circ} 33^{\prime} 33^{\prime \prime} \mathrm{E}$. It covers an area of about $75.23 \mathrm{~km}^{2}, 10.03 \mathrm{~km}$ from east to west, and $7.50 \mathrm{~km}$ from north to south. It is situated in the arid continental climate area with little rain and intensive evaporation. The average annual rainfall is $160.94 \mathrm{~mm}$ and the average annual evaporation value is $1792.64 \mathrm{~mm}$. The maximum and minimum temperatures are $25.18^{\circ} \mathrm{C}$ and $-6.73^{\circ} \mathrm{C}$, respectively. The ground elevation varies from $1120 \mathrm{~m}$ to $1123 \mathrm{~m}$ and tilts smoothly from northwest to southeast. The area consists of diluvial inclined plain and flood-lacustrine plain.

3.2. Materials. The water source of Shizuishan City pumps water from the confined aquifer, so we must evaluate the groundwater quality to make sure whether the groundwater is drinkable. Ten groundwater samples were collected from the water source in April 2009, which were taken from the third confined aquifer. Samples were collected in precleaned plastic polyethylene bottles for physicochemical analysis. Prior to sampling, all the sampling containers were washed and rinsed thoroughly with the groundwater to be taken for analysis.

\section{Result and Discussion}

4.1. Parameters Analysis. Groundwater quality depends on various chemical constituents and their concentrations, which are mostly derived from the geological stratum of the particular region. Thus it is necessary to find some useful indicators, both chemical and physical, to monitor groundwater quality changes. The individual parameters are given as minimum, maximum, average, and standard deviation of the collected samples in the specific area.

Seen from Table 1 and Figure 1, there are mainly six ions in the groundwater $\mathrm{Na}^{+}, \mathrm{Mg}^{2+}, \mathrm{Ca}^{2+}, \mathrm{Cl}^{-}, \mathrm{SO}_{4}{ }^{2-}$, $\mathrm{HCO}_{3}{ }^{-}$). They have indirect influence on other parameters of groundwater, such as TDS, TH, and conductivity, thus they can affect groundwater quality to some extent.

Total hardness $(\mathrm{TH})$ is closely related to daily life and industry; water with high $\mathrm{TH}$ is not suitable for drinking, washing, and industry. Besides, it may lead to some diseases. The maximum $\mathrm{TH}$ is $400.05 \mathrm{mg} / \mathrm{L}$ in $\mathrm{W} 741$; the minimum is $84.1 \mathrm{mg} / \mathrm{L}$ in W44. TDS reflects the total concentration of dissolved solids; the high TDS is maybe caused by mineral weathering. The TDS ranges from a minimum of $259.31 \mathrm{mg} / \mathrm{L}$ in W279 to a maximum of $665 \mathrm{mg} / \mathrm{L}$ in W75.

COD reflects the organic matter's concentration; whether water is polluted by organics can be judged from the value of COD. The highest value of COD is $2.84 \mathrm{mg} / \mathrm{L}$ in W44; the lowest value is $0.44 \mathrm{mg} / \mathrm{L}$ in W279. COD is slightly higher, which may be due to the organic pollution.

Fluoride in small amount is good for preventing dental caries, but high concentration causes health risk such as dental fluorosis and skeletal fluorosis [16]. Fluoride-bearing minerals in the rocks and their interaction with water and 
TABLE 1: Statistical analysis for physicochemical parameters of groundwater.

\begin{tabular}{lcccc}
\hline Parameters & Max & Min & Average & Std. Dev. \\
\hline TH & 400.05 & 84.1 & 199.08 & 504.67 \\
TDS & 665 & 259.31 & 1.37 & 102.43 \\
$\mathrm{COD}$ & 2.84 & 0.44 & 123.5 & 0.79 \\
$\mathrm{Na}^{+}$ & 200 & 57 & 2.25 & 48.52 \\
$\mathrm{~K}^{+}$ & 4.87 & 0.94 & 17.29 & 1.33 \\
$\mathrm{Mg}^{2+}$ & 29.68 & 7.8 & 49.44 & 8.98 \\
$\mathrm{Ca}^{2+}$ & 103.67 & 20.8 & 89.79 & 26.15 \\
$\mathrm{Cl}^{-}$ & 160.9 & 34.09 & 98.91 & 33.93 \\
$\mathrm{SO}_{4}{ }^{2-}$ & 213.4 & 2.45 & 264.22 & 81.08 \\
$\mathrm{HCO}_{3}{ }^{-}$ & 395.96 & 192.2 & 0.58 & 57.41 \\
$\mathrm{~F}^{-}$ & 1.13 & 0.1 & & 0.46 \\
\hline
\end{tabular}

Note: Unit mg/L for all parameters.
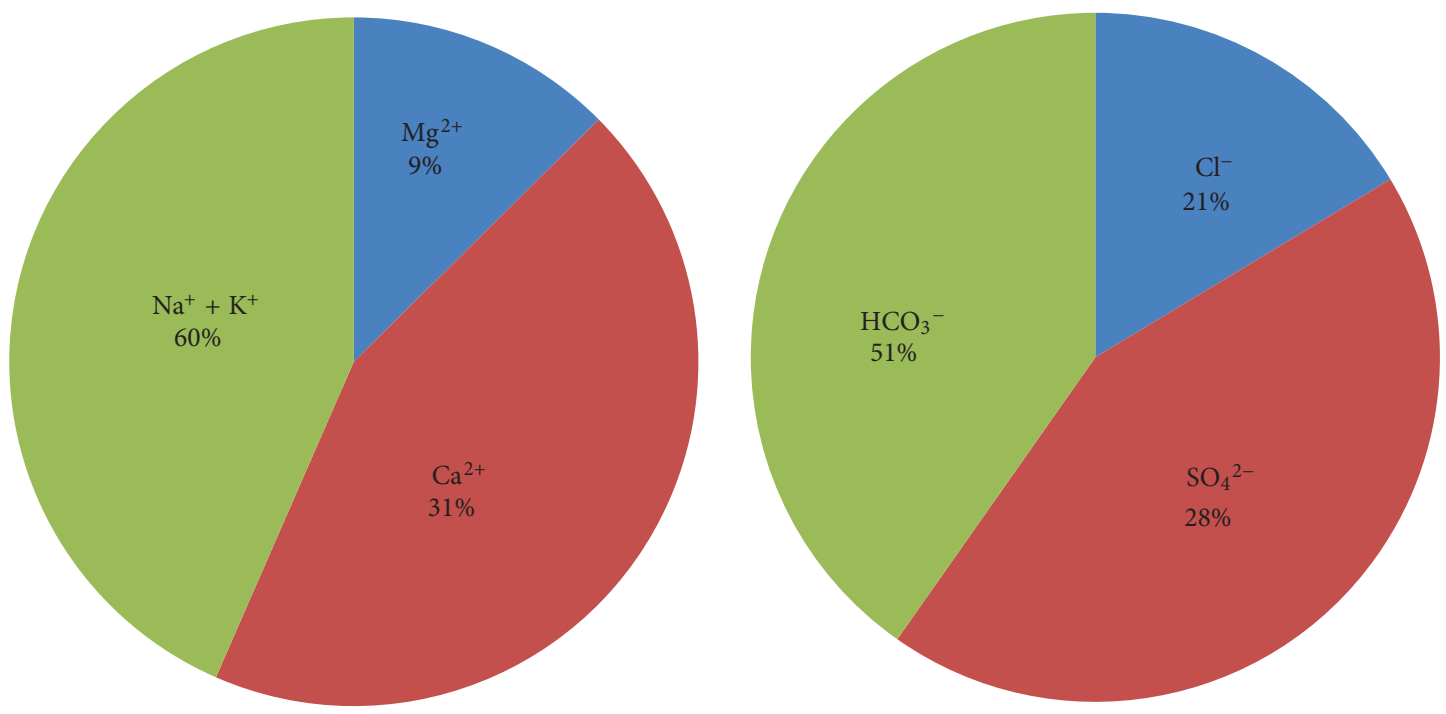

FIGURE 1: Pipe chart of groundwater ions equivalents.

agricultural activities are considered to be the main cause for fluoride in groundwater. In this case, the fluoride ranges from $0.1 \mathrm{mg} / \mathrm{L}$ to $1.13 \mathrm{mg} / \mathrm{L}$, and there is no values exceed the permissible limits.

Volatile phenol, As, $\mathrm{Hg}, \mathrm{Cr}, \mathrm{Ag}$, and other heavy metals are important for assessing groundwater quality; if their concentrations are too high, human health will be under threat. Fortunately, these indexes in this study are all within the permissible limits.

Hydrochemical concepts help to elucidate mechanisms of flow and transport in groundwater systems. In this paper, Piper plot is used to infer hydrogeochemical facies of groundwater. Seen from Figure 2 that the major chemical types of water samples fall into $\mathrm{Cl} \cdot \mathrm{HCO}_{3}-\mathrm{Na}$ type, $\mathrm{Cl} \cdot \mathrm{HCO}_{3}-$ $\mathrm{Na} \cdot \mathrm{Ca}$ type, $\mathrm{Cl} \cdot \mathrm{SO}_{4} \cdot \mathrm{HCO}_{3}-\mathrm{Na} \cdot \mathrm{Ca}, \mathrm{Cl} \cdot \mathrm{SO}_{4} \cdot \mathrm{HCO}_{3}-\mathrm{Na} \cdot \mathrm{Ca} \cdot \mathrm{Mg}$ type and some mixed. Seen from the plot, alkalis ( $\mathrm{Na}$ and $\mathrm{K}$ ) exceed alkaline earths $(\mathrm{Ca}$ and $\mathrm{Mg}$ ) and strong acids $(\mathrm{Cl}$ and $\left.\mathrm{SO}_{4}\right)$ exceed weak acids $\left(\mathrm{HCO}_{3}\right.$ and $\left.\mathrm{CO}_{3}\right)$.

4.2. Mass Balance Simulations. Mass balance simulation is mainly used for studying the chemical reaction during the process of groundwater flow. In the method, two points (e.g., $\mathrm{A}$ and $\mathrm{B}$ ) in the flow path are considered to be the study subjects. The chemistry of A in the upstream is considered to be the initial water quality, and the chemistry of $\mathrm{B}$ in the downstream is considered to be the final water quality. According to the chemical reactions between groundwater and aquifer, the quantities of mineral dissolution and precipitation between $\mathrm{A}$ and $\mathrm{B}$ can be calculated using the mass balance principle. On the basis of that, the chemistry changes in groundwater can be analyzed. In general, mass balance simulation is based on the following equation [17]:

$$
\sum_{j=1}^{n} a_{i j} x_{j}=b_{i}
$$

where $a_{i j}$ is the stoichiometric number of the $i$ th element in the $j$ th mineral. $x_{j}$ is the dissolved mole of the $j$ th mineral, if the value is positive, it means that the jth mineral is dissolved, whereas the negative value indicates the $j$ th mineral is precipitated. $b_{i}$ is the increments of the $i$ th element between $\mathrm{A}$ and $\mathrm{B}$. 


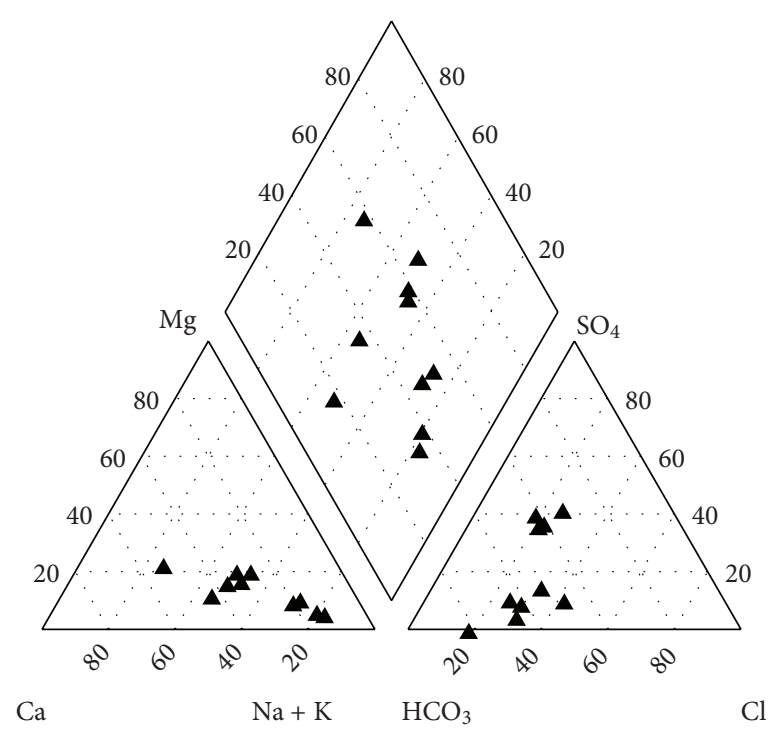

FIgURE 2: Piper plot of groundwater samples.

TABLE 2: Groudwater chemical analysis results in the simulation path (mg/L).

\begin{tabular}{lccccccccc}
\hline & $\mathrm{pH}$ & $\mathrm{K}^{+}$ & $\mathrm{Na}^{+}$ & $\mathrm{Ca}^{2+}$ & $\mathrm{Mg}^{2+}$ & $\mathrm{HCO}_{3}{ }^{-}$ & $\mathrm{Cl}^{-}$ & $\mathrm{SO}_{4}{ }^{2-}$ & $\mathrm{F}^{-}$ \\
\hline W279 & 8.15 & 1 & 57 & 34.56 & 10.47 & 238.83 & 34.09 & 2.45 & 0.12 \\
W75 & 7.91 & 1.88 & 128 & 65.7 & 29.2 & 219.2 & 102.1 & 213.4 & 1 \\
\hline
\end{tabular}

TABLE 3: Reaction equations.

\begin{tabular}{lc}
\hline & Reaction equation \\
\hline Gypsum & $\mathrm{CaSO}_{4} \cdot 2 \mathrm{H}_{2} \mathrm{O}=\mathrm{Ca}^{2+}+\mathrm{SO}_{4}{ }^{2-}+2 \mathrm{H}_{2} \mathrm{O}$ \\
Calcite & $\mathrm{CaF}_{2}=\mathrm{Ca}^{2+}+2 \mathrm{~F}^{-}$ \\
Halite & $\mathrm{CaCO}_{3}=\mathrm{Ca}^{2+}+\mathrm{CO}^{2-}$ \\
Dolomite & $\mathrm{NaCl}=\mathrm{Na}^{+}+\mathrm{Cl}^{-}$ \\
Ion exchange & $\mathrm{CaMg}\left(\mathrm{CO}_{3}\right)_{2}=\mathrm{Ca}^{2+}+\mathrm{Mg}^{2+}+2 \mathrm{CO}_{3}{ }^{2-}$ \\
\hline
\end{tabular}

In this case, groundwater flows from northwest to southeast, W279 is in the upstream, W75 is in the downstream, so the simulation path is from W279 to W75. The chemical analysis results of sample W279 and W75 are showed in Table 2. Saturation index (SI) is the common index to do the hydro-geochemical research, and it is applied to determine the saturation state of minerals in groundwater [17].

The mineral facies are chosen based on the analysis result of groundwater quality, the main components of groundwater, and the occurrences conditions [18]. In the study area, the main cations are $\mathrm{Na}^{+}, \mathrm{Ca}^{2+}, \mathrm{Mg}^{2+}$, the main anions are $\mathrm{HCO}_{3}{ }^{-}, \mathrm{SO}_{4}{ }^{2-}, \mathrm{Cl}^{-}$; thus halite, gypsum, calcite, and dolomite are chosen to be the mineral facies. Although fluoride is the required element for human body, considering its pathogenetic role, fluorite is also decided to be analyzed. Above all, there are five minerals selected.

During the process of groundwater flow, the cations existed in groundwater can be exchanged by other cations existed in the surface of aquifer media. The cation exchange reactions plays important role in the chemical evolution of groundwater [17], so it is included in the mass balance simulation. If the ratio of $\mathrm{Ca}^{2+}$ to $\mathrm{Na}^{+}$decreases in the flow path, it indicates that $\mathrm{Ca}^{2+}$ existed in groundwater may exchange with $\mathrm{Na}^{+}$existed in clay; if the ratio of $\mathrm{Ca}^{2+}$ to $\mathrm{Na}^{+}$ increases, it indicates that $\mathrm{Na}^{+}$existed in groundwater may exchange with $\mathrm{Ca}^{2+}$ existed in clay [19]. The reactions which may occur in the simulation path are listed in Table 3.

Seen from Table 4, $\mathrm{Na}^{+}, \mathrm{Ca}^{2+}$, and $\mathrm{Cl}^{-}$increase in the simulation path, and the increase degree of $\mathrm{Na}^{+}$is greater than that of $\mathrm{Cl}^{+}$, which indicates that there are some other reactions related to $\mathrm{Na}^{+}$occur in the simulation path besides halite's dissolution. The value of $\mathrm{Ca}^{2+} / \mathrm{Na}^{+}$in W279 is 0.3486 , and the value of $\mathrm{Ca}^{2+} / \mathrm{Na}^{+}$in W75 is 0.2951 ; it indicates that the cation exchange reaction may occur in the path.

The mass balance simulation is done by PHREEQC, and the simulation results are listed below.

Seen from Table 5, calcite and dolomite are always oversaturated in the simulation path and have the tendency to precipitate; meanwhile gypsum, fluorite and halite are unsaturated in the simulation path and have the tendency to dissolve into groundwater.

Known from Table 6, calcite precipitates while gypsum, fluorite, halite, and dolomite dissolve in the simulation path. The cation exchange reaction between $\mathrm{Na}^{+}$and $\mathrm{Ca}^{2+}$ occurs at the same time. During the process, $\mathrm{F}^{-}$increases due to the fluorite's dissolution, $\mathrm{Cl}^{-}$increases due to the halite's dissolution, $\mathrm{Mg}^{2+}$ increases due to the dolomite's dissolution, and $\mathrm{SO}_{4}{ }^{2-}$ increases due to the gypsum's dissolution. $\mathrm{Na}^{+}$ increases because of the combined effect of halite's dissolution and the cation exchange reaction. Since the influences of 
TABLE 4: Ratios of $\mathrm{Ca}^{2+} / \mathrm{Na}^{+}$and $\mathrm{Na}^{+} / \mathrm{Cl}^{-}$.

\begin{tabular}{lccccc}
\hline & $\mathrm{Na}^{+}(\mathrm{mmol} / \mathrm{L})$ & $\mathrm{Ca}^{2+}(\mathrm{mmol} / \mathrm{L})$ & $\mathrm{Cl}^{-}(\mathrm{mmol} / \mathrm{L})$ & $\mathrm{Ca}^{2+} / \mathrm{Na}^{+}$ & 0.3486 \\
\hline W279 & 2.4783 & 0.8640 & 0.9603 & 0.3875 \\
W75 & 5.5652 & 1.6425 & 2.8761 & 0.2951 & 0.5168 \\
Difference & 3.0870 & 0.7785 & 1.9158 & -0.0535 \\
\hline
\end{tabular}

TABLE 5: Saturation indices.

\begin{tabular}{lccccrr}
\hline & Gypsum & Fluorite & Calcite & Halite & Dolomite & $\mathrm{CO}_{2}(\mathrm{~g})$ \\
\hline W279 & -3.44 & -3.13 & 0.61 & -7.28 & 1.06 & -2.79 \\
W75 & -1.42 & -1.16 & 0.48 & -6.49 & 0.96 & -2.61 \\
\hline
\end{tabular}

TABLE 6: Dissolution of the mineral facies ( $\mathrm{mmol} / \mathrm{L})$.

\begin{tabular}{ccccccc}
\hline Calcite & Dolomite & Fluorite & Halite & Gypsum & $\mathrm{NaX}$ & $\mathrm{CaX}_{2}$ \\
\hline-1.612 & 0.781 & 0.023 & 1.907 & 2.199 & 1.138 & -0.569 \\
\hline
\end{tabular}

Note: Positive means dissolution, negative means precipitation.

TABLE 7: Comprehensive correlation degrees and extension indexes.

\begin{tabular}{|c|c|c|c|c|c|c|}
\hline \multirow{2}{*}{ Samples } & \multicolumn{4}{|c|}{$K_{i}(P)$} & \multirow{2}{*}{$j^{*}$} & \multirow{2}{*}{ Level } \\
\hline & I & II & III & IV & & \\
\hline W279 & 0.9374 & -0.7077 & -0.8589 & -0.9026 & 1.1359 & I \\
\hline W390 & 0.7434 & -0.4621 & -0.6973 & -0.8297 & 1.305 & I \\
\hline W719 & 0.5338 & -0.1644 & -0.7095 & -0.8132 & 1.4078 & I \\
\hline W741 & -0.1117 & -0.2959 & 0.119 & -0.4583 & 2.2124 & II \\
\hline W16 & -0.132 & 0.3749 & -0.451 & -0.4885 & 1.7464 & I \\
\hline W43 & 0.0962 & 0.3431 & -0.5084 & -0.7263 & 1.7135 & I \\
\hline W44 & 0.4992 & -0.2544 & -0.5663 & -0.7411 & 1.4398 & I \\
\hline W66 & -0.2628 & 0.0508 & 0.2968 & -0.1565 & 2.7885 & II \\
\hline W75 & -0.1554 & 0.0453 & 0.2501 & -0.2702 & 2.4265 & II \\
\hline W69 & -0.3968 & 0.0186 & 0.2233 & -0.1476 & 2.8706 & II \\
\hline
\end{tabular}

TABLE 8: Comparison of the results of the two methods.

\begin{tabular}{lccccccccccc}
\hline Samples & W279 & W390 & W719 & W741 & W16 & W43 & W44 & W66 & W75 & W69 \\
\hline Matter element extension & I & I & I & II & I & I & I & II & II & II \\
Osculating value method & I & I & I & II & II & I & I & III & III & III \\
PCA & I & I & I & II & II & II & III & II & II & II \\
\hline
\end{tabular}

gypsum, fluorite, and dolomite's dissolution on the content of $\mathrm{Ca}^{2+}$ are greater than that of calcite's dissolution and the cation exchange reaction, the concentration of $\mathrm{Ca}^{2+}$ increases. The precipitation of calcite and the dissolution of dolomite together decrease $\mathrm{HCO}_{3}{ }^{-}$. Because the groundwater in this case is confined water and the burial depth is large, it is less connected with the atmosphere, so $\mathrm{pH}$ of the groundwater is mainly affected by the content of alkaline anions, such as $\mathrm{HCO}_{3}{ }^{-}$.

Judged from the dissolution of $\mathrm{NaX}$ and $\mathrm{CaX}_{2}$, the cation exchange reactions is extensive, and the change of $\mathrm{Ca}^{2+}$ is smaller, while the change of $\mathrm{Na}^{+}$is greater, and the changing tendency of $\mathrm{Ca}^{2+} / \mathrm{Na}^{+}$is apparent. Thus we can determine again that $\mathrm{Na}^{+}$increase is due to the combined effect of halite's dissolution and cation exchange reaction.

4.3. Assessment of Groundwater Quality. In this study, eight typical indexes are selected to be the evaluation indexes, which can reflect the physical and chemical characteristics of groundwater. There are TH, TDS, COD, $\mathrm{Ca}^{2+}, \mathrm{Cl}^{-}, \mathrm{SO}_{4}{ }^{2-}$, $\mathrm{HCO}_{3}{ }^{-}$, and $\mathrm{F}^{-}$. The state standard of groundwater quality GB/T14848-93 is chosen to be the evaluation criterion, which is divided into five levels. Considering that there is no evaluation index exceeded the fifth level limit in this study, thus only the first fourth levels are chosen to build the matter elements. 
Based on matter element extension method, groundwater quality is evaluated. The comprehensive correlation degree $K_{i}(P)$ and extension index $j^{*}$ are calculated and shown in Table 7.

Known from Table 7, groundwater quality of W279, W390, W719, W16, W43, and W44 belong to level I, and W741, W66, W75, and W69 belong to level II. The result indicates that groundwater quality in the study area is good as a whole and can be drinkable. Because of the great depth and the protection of aquitard, the confined water is not easy to be polluted. Judged from the value of extension index $j^{*}$, water samples W16 and W43 tend to convert from level I into level II. W741 and W75 tend to convert from level II into level I, while W66 and W69 tend to convert from level II into level III.

Which water sample's quality is better than other's at the same level can be judged by comparing the values of extension indexes. For instance, groundwater quality of both W279 and W16 belongs to level I, but the extension index value of sample W16 is higher than that of W279. It indicates that the attributive degree of W16 to convert into II level water is higher than that of W279. In other words, groundwater quality of W16 is worse than that of W279. The rest can be done in the same way. So groundwater quality of water samples from good to bad can be expressed in the order of W279 > W390 > W719>W44>W43> W16 > W741 > W75 > W66 > W69.

Osculating value method based on entropy weight [13] and principal component analysis method (PCA) [20] are the popular methods to assess groundwater quality, so we also use the two methods to assess groundwater quality of study area and then compare the results obtained from the three methods.

Seen from Table 8, the results obtained from the three different methods are basically similar. Principal component analysis method (PCA) neglects some important information, which may lead some result unreasonable; the evaluated result obtained by using osculating value method based on entropy weight is too restrict. Based on the reasons presented above, the evaluated results obtained from the three methods are different from each other more or less. But on the whole the comparison confirms that the results obtained from matter element extension are reliable and scientific.

\section{Conclusion}

From the mass balance simulation, calcite and dolomite are oversaturated, meanwhile gypsum, fluorite and halite are unsaturated in the simulation path, and the changing tendency of $\mathrm{Ca}^{2+} / \mathrm{Na}^{+}$is apparent. Calcite precipitates, while gypsum, fluorite, halite, and dolomite dissolve in the simulation path. Because of the dissolution and precipitation of minerals, the contents of chemical compositions are changed. Groundwater quality in the study area is evaluated by using the matter element extension method, and results show the groundwater meets the requirement of drinking water standards. It is proved that matter element extension is a reasonable and effective method to evaluate groundwater quality by comparing the results obtained from the other methods. The application of information entropy minimizes the subjective interferences and makes the result more objective and accurate. According to the values of extension indexes, groundwater quality of water samples in the same level can be compared and the tendency of conversion can be judged; it is the unique characteristic of matter element extension method used in this study.

\section{Acknowledgments}

This study is supported by National Natural Science Foundation of China (41172212) and the Special Fund for Basic Scientific Research of Central Colleges, Changan University (CHD2012TD003).

\section{References}

[1] A. A. Bordalo, R. Teixeira, and W. J. Wiebe, "A water quality index applied to an international shared river basin: the case of the Douro River," Environmental Management, vol. 38, no. 6, pp. 910-920, 2006.

[2] W. C. Ip, B. Q. Hua, H. Wong, and J. Xia, "Applications of grey relational method to river environment quality evaluation in China," Journal of Hydrology, vol. 379, no. 3-4, pp. 284-290, 2009.

[3] N. C. Mondal, V. S. Singh, V. K. Saxena, and V. P. Singh, "Assessment of seawater impact using major hydrochemical ions: a case study from Sadras, Tamilnadu, India," Environmental Monitoring and AssessmentEnviron Monit Assess, vol. 177, no. 1-4, pp. 315-335.

[4] L. Liu, J. Zhou, X. An, Y. Zhang, and L. Yang, "Using fuzzy theory and information entropy for water quality assessment in Three Gorges region, China," Expert Systems with Applications, vol. 37, no. 3, pp. 2517-2521, 2010.

[5] S. Zhong, Q. Wang, and B. Jin, "Application of the fuzzy synthetic method to seawater quality evaluation in zhifu bay," Transactions of Oceanology and Limnology, vol. 2, pp. 57-61, 2007.

[6] C. Wen, Matter Element Model and Application, Science and Technology, Literature Press, Beijing, China, 1994.

[7] L. Yang, "Assessment of city environmental quality in Western China based on matter element extension-A case study of Chongqing," Energy Procedia, vol. 5, pp. 619-623.

[8] J. Z. Gong, Y. S. Liu, and W. L. Chen, "Land suitability evaluation for development using a matter-element model: a case study in Zengcheng, Guangzhou, China," Land Use Policy, vol. 29, no. 2, pp. 464-472, 2012.

[9] Y.X. He, A. Y. Dai, J. Zhu, H. Y. He, and F. Li, "Risk assessment of urban network planning in china based on the matter-element model and extension analysis," International Journal of Electrical Power and Energy Systems, vol. 33, no. 3, pp. 775-782, 2011.

[10] M. H. Wang, Y. K. Chung, and W. T. Sung, "Using thermal image matter-element to design a circuit board fault diagnosis system," Expert Systems with Applications, vol. 38, no. 5, pp. 6164-6169, 2011.

[11] J. Tang, C. Y. Wang, N. F. Lin, Z. Y. Li, H. Y. Li, and Z. L. Mao, "Application of matter-element model in soil nutrient evaluation of ecological fragile region," Chinese Geographical Science, vol. 19, no. 2, pp. 168-176, 2009. 
[12] T. Fatemeh, Z. F. Reza, and R. Shabnam, "Fuzzy AHP to determine the relative weights of evaluation criteria and Fuzzy TOPSIS to rank the alternatives," Applied Soft Computing Journal, vol. 10, no. 2, pp. 520-528, 2010.

[13] P. Y. Li, J. H. Wu, and H. Qian, "Groundwater quality assessment based on entropy weighted osculating value method," International Journal of Environmental Sciences, vol. 4, pp. 621-630, 2010.

[14] S. S. Lan, J. Y. Jiang, and B. Wang, "Evaluation of groundwater quality based on matter-element and extension means-taking shallow groundwater of plain areas in lishu for example," Jilin Daxue Xuebao, vol. 39, no. 4, pp. 722-727, 2009.

[15] W. D. Gao and H. R. Zhang, "Groundwater quality assessment based on matter element model," Environmental Science and Management, vol. 32, pp. 169-172, 2007.

[16] J. Baskaradoss, R. Clement, and A. Narayanan, "Prevalence of dental fluorosis and associated risk factors in 11-15 year old school children of Kanyakumari District, Tamilnadu, India: a cross sectional survey," Indian Journal of Dental Research, vol. 19, no. 4, pp. 297-303, 2008.

[17] H. Qian and Z. Y. Ma, Hydrogeochemistry, Geological Publishing House, Beijing, China, 2005.

[18] Q. B. Luo, W. D. Kang, Y. L. Xie, and B. F. Zhao, "Groundwater hydro-geochemistry simulation in the Jingbian Area of the Luohe of Cretaceous," Groundwater, vol. 30, no. 6, pp. 22-24, 2008.

[19] Y. Sun, H. Qian, and X. Wu, "Hydrogeochemical characteristics of groundwater depression cones in Yinchuan City, Northwest China," Chinese Journal of Geochemistry, vol. 26, no. 4, pp. 350-355, 2007.

[20] X. N. Liu and W. Cui, China Water \& Wastewater, vol. 25, no. 18, pp. 105-108, 2009. 

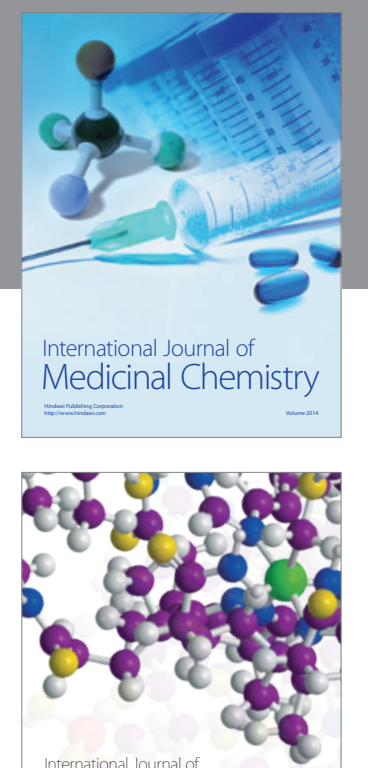

\section{Carbohydrate} Chemistry

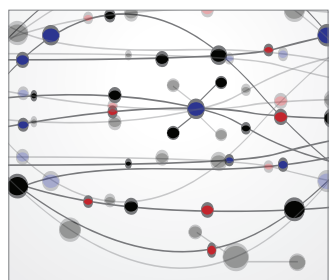

The Scientific World Journal
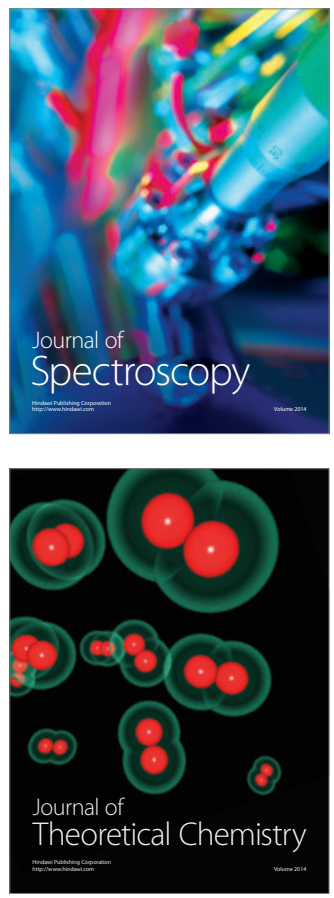
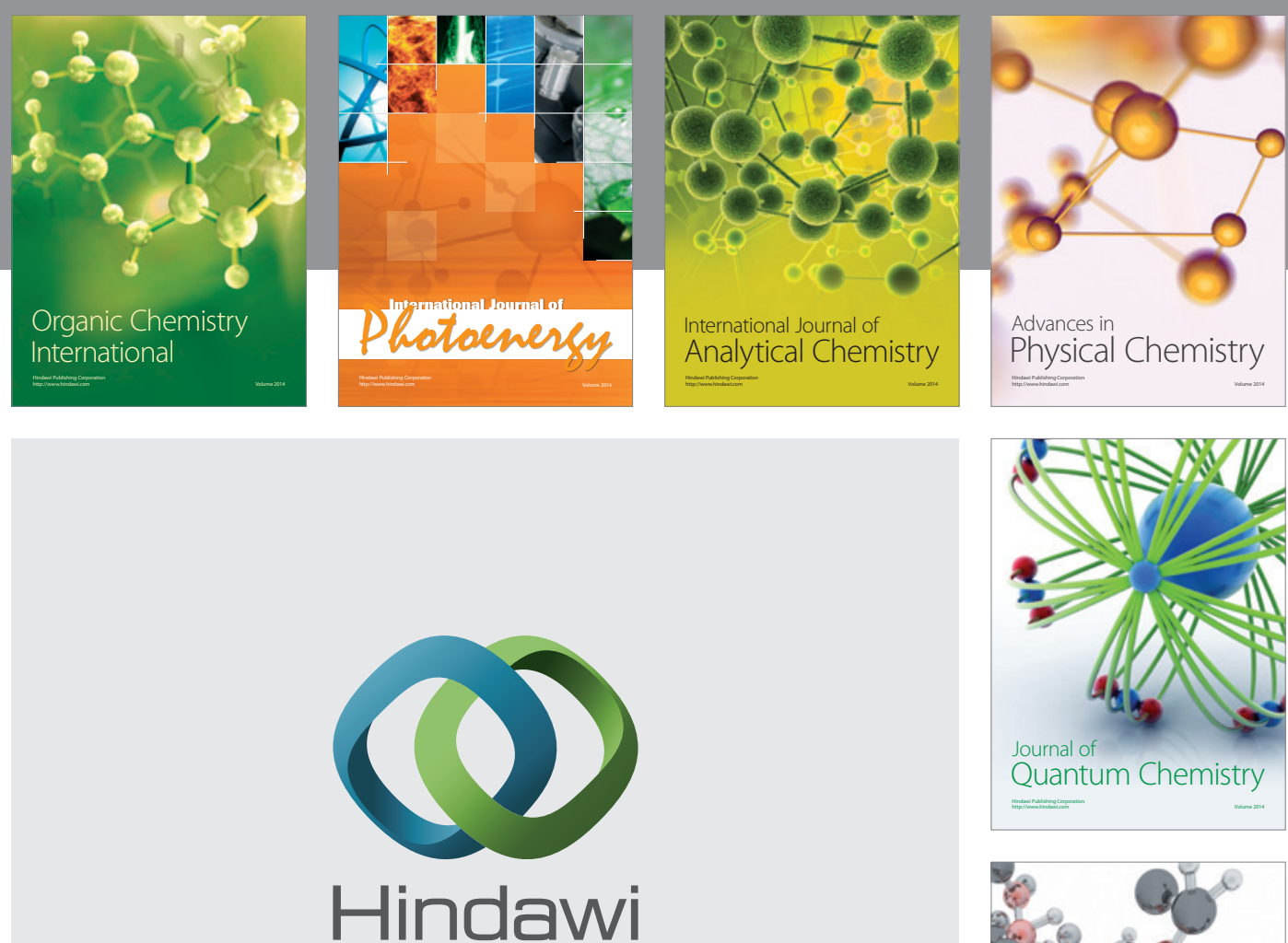

Submit your manuscripts at

http://www.hindawi.com

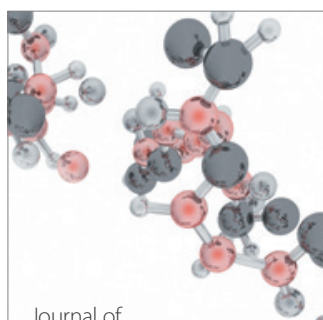

Analytical Methods

in Chemistry

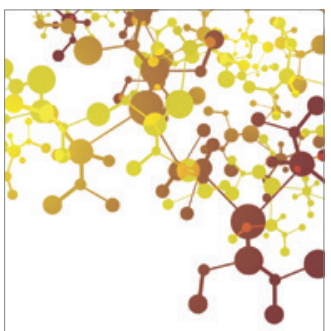

Journal of

Applied Chemistry

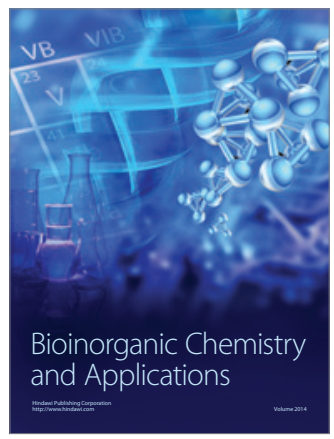

Inorganic Chemistry
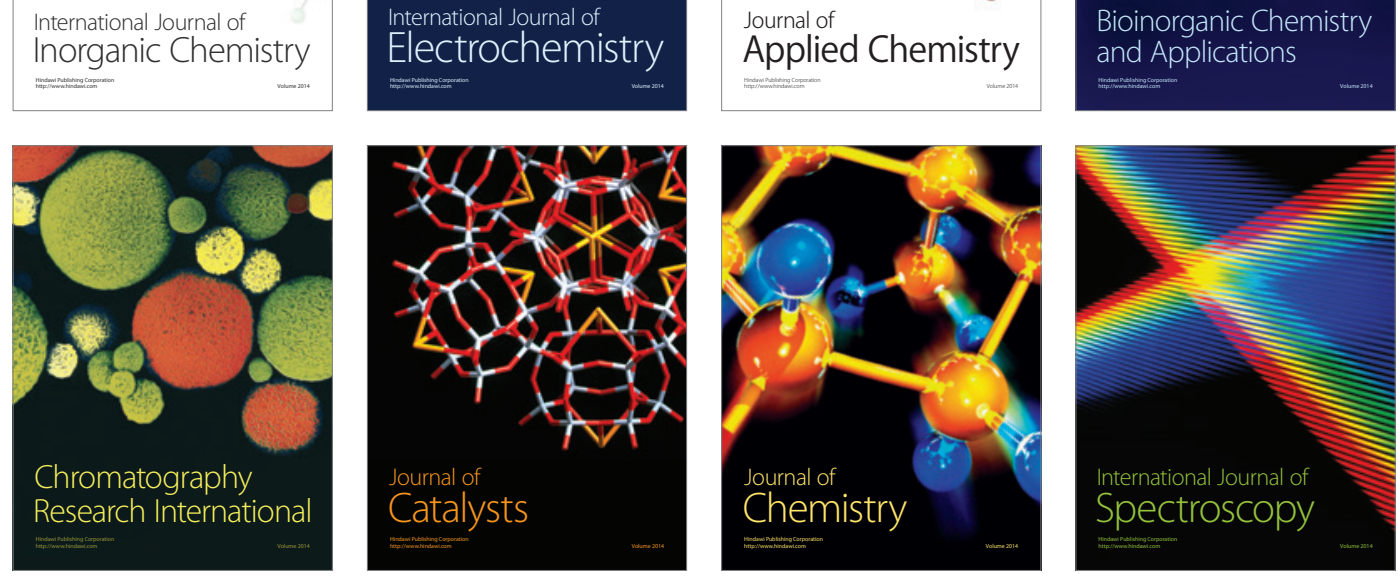